\title{
Arsenic Treatment in Groundwater in Mekong Delta Using Laterite Absorbent
}

\author{
Nguyen Thi Thanh Phuong ${ }^{1}$, Duong Thi Kieu Trang ${ }^{1}$, Tran Le Luu ${ }^{2, *}$ \\ ${ }^{1}$ Institute of Environment and Natural Resources, Viet Nam National University, Ho Chi Minh City, Viet Nam \\ ${ }^{2}$ Department of Mechatronics and Sensor Systems Technology, Vietnamese German University, Binh Duong, Viet Nam
}

Email address:

luu.tl@vgu.edu.vn (T. L. Luu)

${ }^{*}$ Corresponding author

\section{To cite this article:}

Nguyen Thi Thanh Phuong, Duong Thi Kieu Trang, Tran Le Luu. Arsenic Treatment in Groundwater in Mekong Delta Using Laterite Absorbent. Science Journal of Chemistry. Vol. 5, No. 6, 2017, pp. 95-100. doi: 10.11648/j.sjc.20170506.14

Received: October 12, 2017; Accepted: October 23, 2017; Published: December 12, 2017

\begin{abstract}
Arsenic contamination in groundwater has led to pandemic influenza and many disease in Viet Nam and its neighbour country. It is estimated that about 57 million people in the world are affected by Arsenic contamination in drinking water. In Viet Nam, especially in Mekong River Delta, the Arsenic was detected in drinking water is up to $3000 \mu \mathrm{g} / \mathrm{l}$, many times higher value allowed by the World Health Organization (WHO) of $10 \mu \mathrm{g} / \mathrm{l}$. In this study, the laterite absorbent was used to treat Arsenic in groundwater in Mekong River Delta in Viet Nam. It is determined that laterite is a powerful absorbent for Arsenic removal in groundwater.
\end{abstract}

Keywords: Groundwater, Arsenic, Mekong Delta, Laterite

\section{Introduction}

Arsenic pollution (As) in groundwater is one of the major threats to human health. As can cause serious diseases such as skin cancer, bladder, kidney, lung, and many other diseases. The World Health Organization (WHO) recommends the limitation of As is $10 \mu \mathrm{g} / \mathrm{L}$ in drinking water [2]. Large amounts exposure of As for a long time can lead to As poisoning. Therefore, finding the novel solution to treat As in groundwater is very necessary. As common presence is $\mathrm{As}^{3+}$ (arsenite) or $\mathrm{As}^{5+}$ (arsenate) [3]. Arsenite compounds are 50 times more toxic than arsenates, and arsenite is more soluble in water than arsenate at the same duration time, respectively [4]. Arsenates are adsorbed quite strongly on various mineral surfaces, particularly iron/oxide hydroxide, while the adsorption capacity of arsenite is poor [5].

Currently in Vietnam and around the world, there are many technologies have been researched and applied in practice to remove As toxins in groundwater and surface water. Air injection technology is commonly used to treat groundwater contaminated with As for living in some areas of the Mekong River Delta where water is contaminated with alum. With this technology, $\mathrm{Fe}^{2+}, \mathrm{Mn}^{2+}$ are oxidized to $\mathrm{Fe}^{3+}$ and $\mathrm{Mn}^{4+}$ and other reducing agents such as $\mathrm{As}^{3+}$ are also oxidized to $\mathrm{As}^{5+}$, thus reducing the toxicity of As in water. The sedimentation technology is the As treatment method used by local people, which is similar to the raindrops with the sunlight and oxygen to settle and remove As. [7]. These are other safe technologies without using chemical agents in the progress. However, the level of As removal efficiency is not high. As removal technology with the filter system has many advantages to filter with a significant removal efficiency of As. But the cost of treatment is quite high due to the use of many layers of filter materials such as activated carbon, sand, gravel. Infected with high As concentration in groundwater in Thanh Binh district, Dong Thap province. The treatment method of As by oxidation combined with flocculation, sedimentation and filtration and the treated water achieved standard concentration of As water. Some other technologies are also effective for removing As in household water, but need to use a mixture of iron sulphate powder and calcium hypochlorite. Thus, although As was removed, other toxins such as iron and chlorine are still presented in the drinking water [8-10].

Laterite is one of the less weathered soils in tropical conditions. This weathering product is mostly distributed in hilly areas of countries with high annual mean temperatures and heavy rainfall. In Asia, laterite is very popular in China, 
India, Bangladesh, Vietnam and Indonesia. In Vietnam, laterite is widely distributed in the hilly land between the North and South and belongs to the feralite soil group (FAO-Unesco Land Classification). Laterite has a high hardness, very low permeability, high iron content and aluminium content [8]. Thus laterite is capable of adsorbing some of the chemical ions that polluted the water. Therefore, this study proposes the adsorption of As in water by laterite materials in order to test the adsorption capacity of As in water of natural laterite products to select this material as As filtering material in groundwater. At the same time the absorption capacity was indicated when using the columnar model. This is one of the environmentally friendly technologies with low costs, suitable to the real conditions of Vietnam.

\section{Materials and Methods}

All chemicals used are reagents used in the analysis and used without further purification. All the solutions were prepared in distilled water ( 2 times). Solutions of $\mathrm{Na}_{2} \mathrm{HPO}_{4}$, $\mathrm{Na}_{2} \mathrm{SO}_{4}, \mathrm{NaOH}, \mathrm{HCl}, \mathrm{NaCl}, \mathrm{Na}_{2} \mathrm{CO}_{3}$ (all from Merck) are diluted at $1000 \mathrm{mg} / \mathrm{l}$ and stocked when required. The $\mathrm{pH}_{\mathrm{PZC}}$ equilibrium point of the material was determined by two experiments with $\mathrm{KCl} 0.1 \mathrm{M}$ and $\mathrm{KCl} 0.01 \mathrm{M}$ solutions. For preliminary determination of the non-pH-value of the material, $5 \mathrm{ml}$ of $\mathrm{KCl} 0.1 \mathrm{M}$ is mixed, and adjusted $\mathrm{pH}$ with $0.1 \mathrm{M} \mathrm{HCl}$ solution or $0.1 \mathrm{M} \mathrm{NaOH}$ solution to obtain $\mathrm{pHi}$ values: $2,4,6$, 7, 8, 10 and 12. Pour the standard solutions pHi above the triangles containing the mixed adsorbent $(0.5$ grams of laterite), tightly closed, shaked for 48 hours. To settle, filter residue by filter paper, re-measured the $\mathrm{pH}$ value called $\mathrm{pHf}$ : $\Delta \mathrm{pH}=\mathrm{pH}_{\mathrm{f}}-\mathrm{pH}_{\mathrm{i}}$.

The structure morphology of the adsorption material was determined by scanning electron microscope energy-dispersive X-ray spectroscopy (SEM-EDX) JEOL JSM-5800. For BET (Brunauer, Emmett and Teller) analysis using NOVA 1000e of Quantechrome Nova Win. The study on the real groundwater sample was carried out in Thang Binh district, Dong Thap province with an as input concentration of $570 \mu \mathrm{g} / \mathrm{l}$. All measurements of As concentration in the solution were carried out using the AAS atomic absorption spectrophotometer.
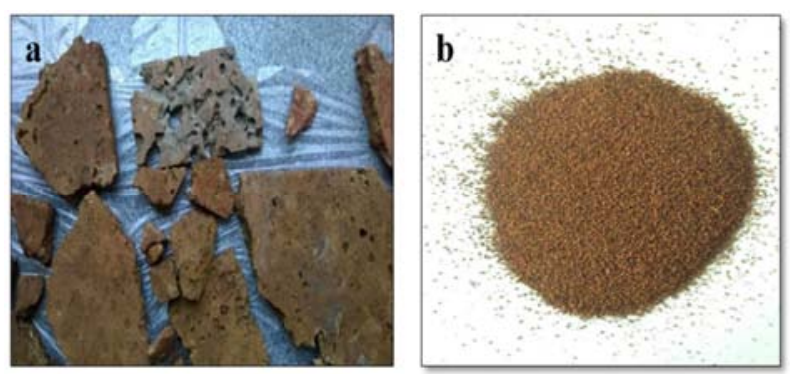

Figure 1. Pre-collected rock samples (a) and powder after refining (b).

The samples of the rock samples collected in Thach That Hanoi were thoroughly washed with tap water to remove unwanted impurities (organic impurities, worms, sand, dust and dried). Subsequently, fine grinding samples in the size range of $0.15-0.42 \mathrm{~mm}$ with Fe content measured in EDX yielded of $6.52 \%$. They are screened, thoroughly washed (15-20 times) with tap water to remove red iron, and then washed with distilled water. Finally, the powder are dried in a hot oven at $110^{\circ} \mathrm{C}$ overnight. These powder particles are prepared to be used to adsorb As. Determination of optimal parameters and factors affecting experiments by fixed borosilicate glass column with the parameters of the column as follows: column height: $\mathrm{h}=22 \mathrm{~cm}$, column diameter: $\mathrm{d}=2$, $5 \mathrm{~cm}$, column capacity: $\mathrm{V}=\Pi . \mathrm{R} 2 . \mathrm{h}=3.14$. (1.25) $2.22=108$ $\mathrm{ml}$. Columns are buffered with beech soil between two supported layers of glass cotton to prevent the buoyancy of the adsorbent material. Identification the adsorption isotherms to determine the volume and adsorption mechanism of the material. The isothermal equation follows the Langmuir rule and Freundlich's law, which describes the relationship between the adsorption capacity and the concentration of the adsorbed at equilibrium. Isothermal equations are used to calculate the maximal adsorption capacity of laterite materials.

\section{Result and Discussion}

\subsection{The EDX Spectra}

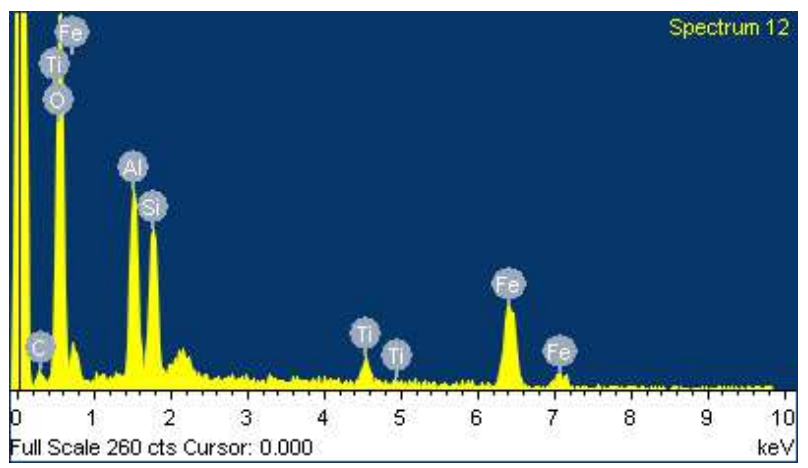

Figure 2. The EDX spectra of laterite material.

Table 1. The chemical composition of laterite material.

\begin{tabular}{lll}
\hline Element & \% mass & \% mole \\
\hline $\mathrm{C}$ & 5.15 & 9.55 \\
$\mathrm{O}$ & 44.65 & 62.24 \\
$\mathrm{Al}$ & 10.27 & 8.49 \\
$\mathrm{Si}$ & 9.04 & 7.18 \\
$\mathrm{Ti}$ & 3.17 & 1.48 \\
$\mathrm{Fe}$ & 27.72 & 11.07 \\
\hline
\end{tabular}

Figure 2 and Table 1 show the chemical composition of laterite materials before adsorption. According to the results of the EDX of the laterite material shown in Figure 2, at the voltage of $0-2 \mathrm{kV}$, the emission of X-rays corresponds to the atomic number of the elements $\mathrm{C}, \mathrm{Fe}, \mathrm{Al}, \mathrm{Si}, \mathrm{O}$ in which $\mathrm{Fe}$ is the electronic element interacting to create the largest wavelength. At higher voltages, the interactions between electrons emitting electrons from the elements decrease, but $\mathrm{Fe}$ is still the interaction element that produces large-scale 
X-rays. From the results shown in Table 1, O (62.24\%), Fe atoms $(11.07 \%), \mathrm{Al}(8.49 \%)$ and $\mathrm{Si}(7.18 \%)$ also accounted for a significant proportion. The chemical composition of the iron oxide (III) is $44.59 \%$, followed by components of aluminum oxide $(21.84 \%)$ and $\mathrm{Si}(21.81 \%)$. This result shows that the minerals with the main components are $\mathrm{Fe}, \mathrm{Al}, \mathrm{Si}$, especially the Fe element, which is the adsorption center of As and also from this result allows us to predict the mineral composition of the laterite material. Hematite $\left[\mathrm{Fe}_{2} \mathrm{O}_{3}\right.$, $\left.\alpha-\mathrm{Fe}_{2} \mathrm{O}_{3}\right]$, quartz $\left[\mathrm{SiO}_{2}\right]$ kaolinite $\left[\mathrm{Al}_{2}\left(\mathrm{Si}_{2} \mathrm{O}_{5}\right)(\mathrm{OH})_{4}\right]$. The obtained results are quite similar to the results of research by Nguyen Trung Minh on the percentage of chemical elements in laterite. In that study, the results of chemical composition of laterite in Binh Yen - Ha Tay are as follows: $\mathrm{Al}_{2} \mathrm{O}_{3}: 23.63 \%$, $\mathrm{Fe}_{2} \mathrm{O}_{3}: 29.07 \%, \mathrm{SiO}_{2}: 26.10 \%$ and laterite in Tho Tan, Thanh Hoa: $\mathrm{Al}_{2} \mathrm{O}_{3}: 17.64 \%, \mathrm{Fe}_{2} \mathrm{O}_{3}: 42.53 \%, \mathrm{SiO}_{2}: 27.71 \%$ [2]. From
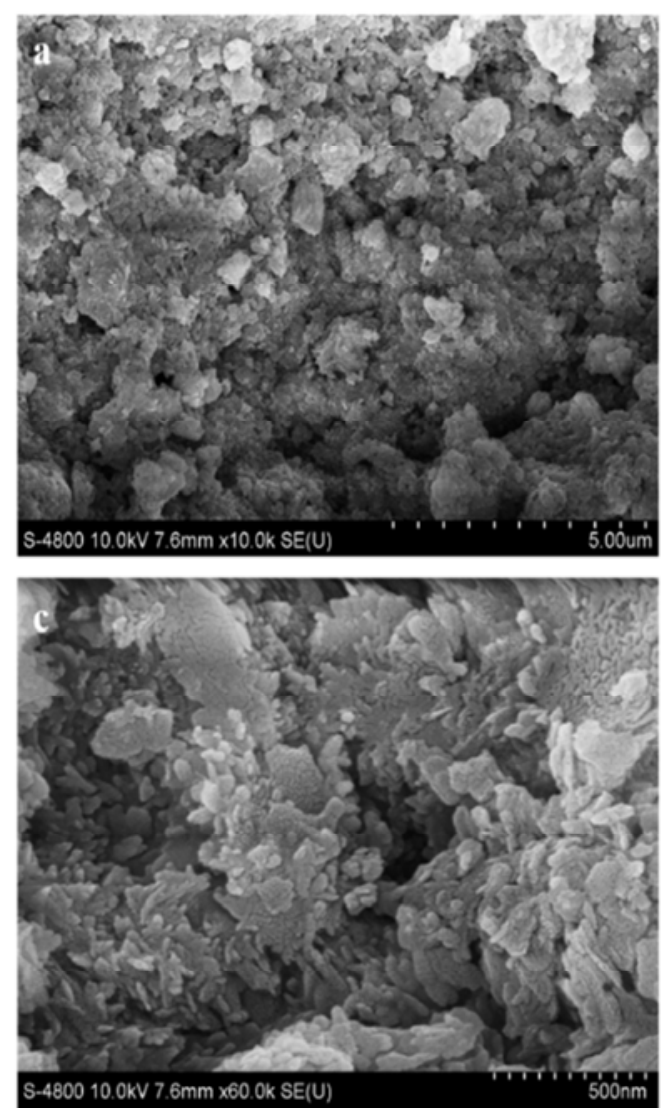

Figure 3. SEM image of laterite material with difference magnification 10,000; 30,000; 60,000; 80,000 times.

\subsection{BET Area}

The specific surface area is an important factor for the absorption capacity of the material. The larger the area of the surface, the more favorable the reaction molecules will be in contact with the active centers of the surface, thereby increasing the absorption capacity by the larger of the surface area. To measure the specific surface area of the laterite material before adsorption, the BET measurement method was used with the analytical results shown in Figure 4. The results here it can be commented that laterite species in different parts of Vietnam have different chemical compositions, but they have common characteristics, which are rich in $\mathrm{Fe}, \mathrm{Al}$ and $\mathrm{Si}$ elements.

\subsection{Surface Morphology}

Images of the surface morphology of scanned electron microscope (SEM) with different magnifications of 10000 , 30000, 60000, and 80000 were shown in Figure 3. The results indicated that the surface of the material is not homogeneous, the granular, rod, rhombus, and thorium crystals on the surface increase the porosity of the material. At a magnification of 800,000 times, the image expresses the porous, called hollow spaces of varying sizes, thereby producing microtubules for the adsorbent material.
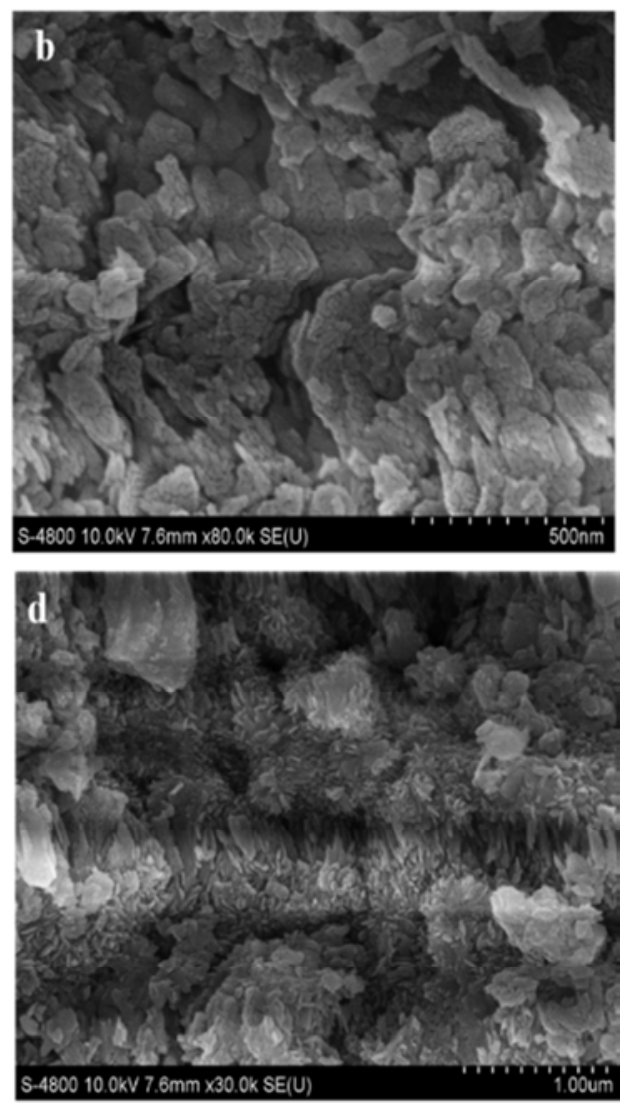

of the BET shooting showed that the specific surface area of laterite particle sizes from $0.15 \mathrm{~mm}$ to $0.42 \mathrm{~mm}$ are relatively large $\left(30,712 \mathrm{~m}^{2} / \mathrm{g}\right)$, suitable for adsorption materials. This result is significantly greater than that of some laterite studies by Sanjoy K. Maji et al. at a particle size of $0.164 \mathrm{~mm}$, a surface area of $15.365 \mathrm{~m}^{2} / \mathrm{g}$ [9] or research by Abhijit Maiti et al. at $0.55 \mathrm{~mm}-0.36 \mathrm{~mm}$ particle size, the specific surface area is $18.05 \mathrm{~m}^{2} / \mathrm{g}$ [10]. 


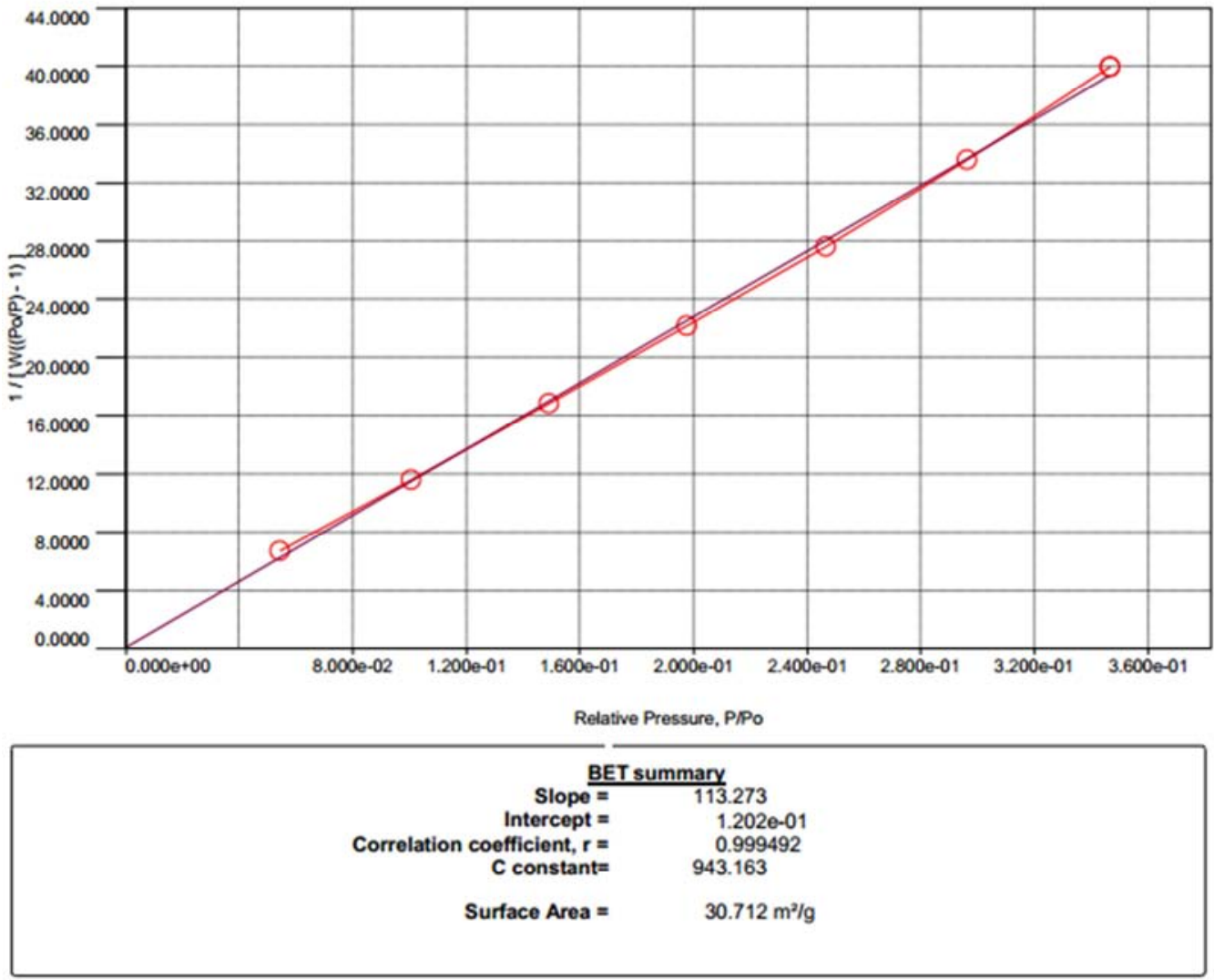

Figure 4. BET result of laterite sample.

\subsection{The Point of Zero Charge $p H_{P Z C}$ of Laterite}

The results in Figure 6 showed that in experiments with $0.1 \mathrm{M}$ $\mathrm{KCl}$ solution, the correlation coefficient $\mathrm{R} 2=0.993$, and in the $\mathrm{KCl} 0.01 \mathrm{M}$ experiment, the correlation coefficient $\mathrm{R} 2=0.991$ and the $\mathrm{pH}$ of laterite in both experiments were about 6.9-7.2. Thus, the $\mathrm{pH}_{\mathrm{PZC}}$ of laterite at the same amount of $\mathrm{KCl}$ does not depend on the concentration of $\mathrm{KCl}$. Patching the duplication of the diagonal of the two curves demonstrates a good fit between experiment and theory. To obtain more accurate results, continue to precisely determine the charge point by dividing the $\mathrm{pHi}$ distance as follows: $6.2,6.4,6.6,6.8$ and 7.0. The $\mathrm{KCl} 0.1 \mathrm{M}$ concentration on the graph demonstrating the dependence of $\Delta \mathrm{pH}$ on $\mathrm{pHi}$ is $\mathrm{y}=1.31 \mathrm{x}-8.883$ with a correlation coefficient of $\mathrm{R} 2=0.969$ showing the good fit between experiment and theory (the first line). With $\mathrm{KCl} 0.01 \mathrm{M}$, the graph demonstrating the dependence of $\Delta \mathrm{pH}$ on $\mathrm{pHi}$ is $\mathrm{y}=1.29 \mathrm{x}-8.716$ with a correlation coefficient of R2 $=0.981$ indicating a good agreement between experiment and theory.

\section{$\mathrm{KCl} 0.01 \mathrm{M} \quad \mathrm{a}$}

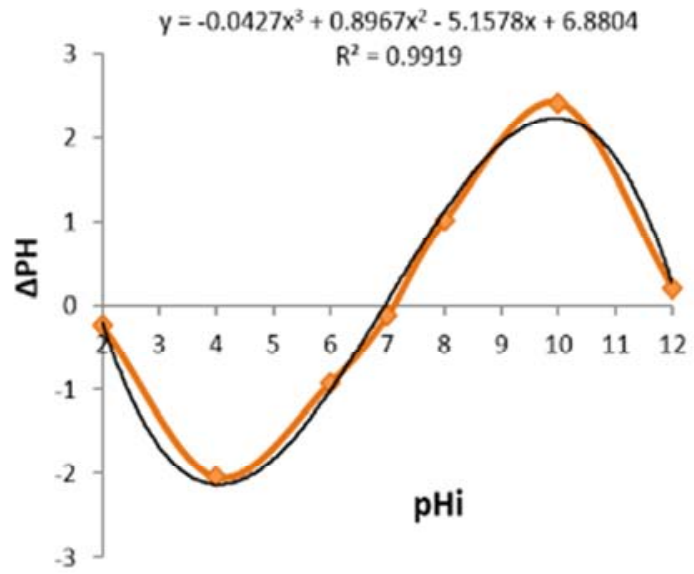

$\mathrm{KCl} 0.01 \mathrm{M} \quad \mathrm{b}$

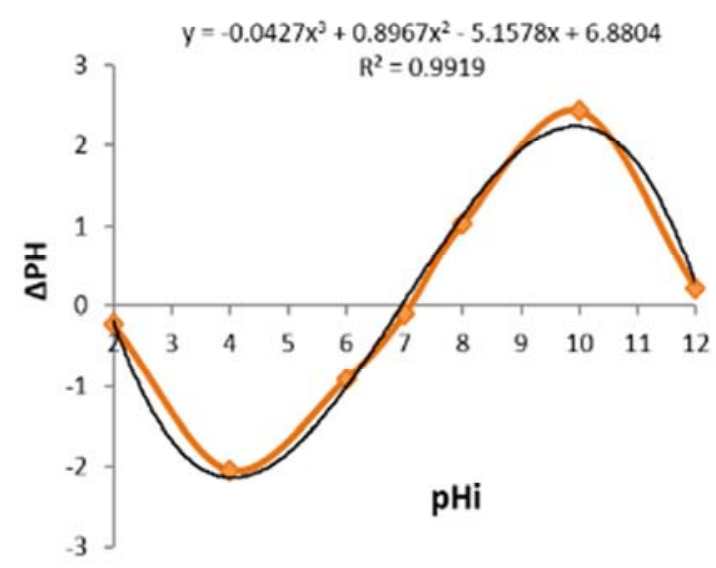

Figure 5. $p H_{P Z C}$ result of laterite with difference $\mathrm{KCl}$ concentration. 


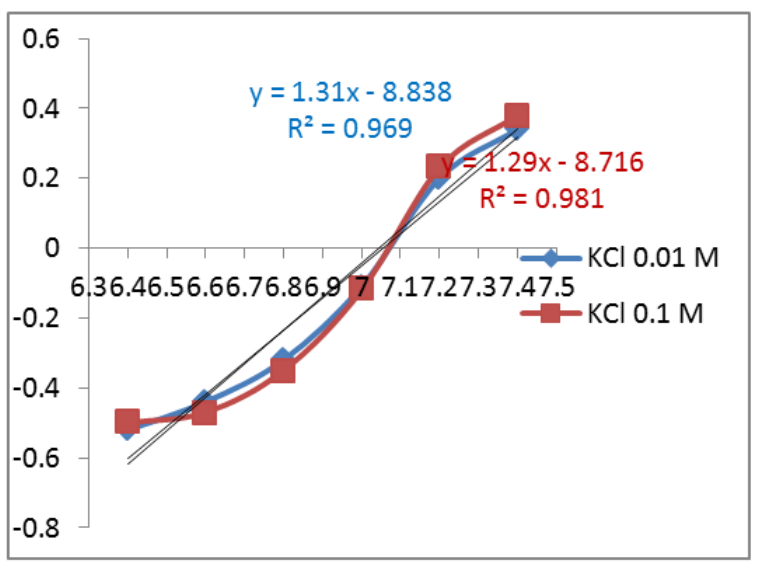

Figure 6. $p H_{P Z C}$ result of laterite.

The $\mathrm{pH}$ value used to describe the PZC of the material in the strong electrolyte solution is the $\mathrm{KCl}$ salt based on the mechanism: when the $\mathrm{pH}$ is lower than the $\mathrm{pH}_{\mathrm{PZC}}$ value, the system is called below PZC, then in aqueous solution. Give more $\mathrm{H}^{+}$ions than $\mathrm{OH}^{-}$ions, so the adsorption surface is positively charged. Conversely, when the $\mathrm{pH}$ is greater than the $\mathrm{pH}_{\mathrm{PZC}}$ value, the system is called above the $\mathrm{PZC}$, the adsorption surface is negative. Figure 6 shows the results of the preliminary determination of PZC of laterite material in $0.1 \mathrm{M}$ and $0.01 \mathrm{M} \mathrm{KCl}$ solutions. At $\mathrm{pH} 7.0$ and 7.2, the difference in $\mathrm{pH}$ value is not so great as to predict the PZC of the material. From this resulting graph shows that the charge point of lateritee is determined in $\mathrm{KCl}$ solution in the range of $\mathrm{pH}$ of 7.05-7.10. This result is quite similar to previous studies of laterite materials, as reported by Nguyen Trung Minh, the PZC of laterite was 7.18-7.27 [2] or research by Sanjoy K. Maji et al. with PZC of laterite was 6.96 and so on [10-17].

\subsection{Treatment of Groundwater}

The lateral adsorption capacity of laterite in real groundwater samples with actual groundwater samples was collected in Thanh Binh district, Dong Thap province. From the analysis of raw water samples, the concentration of As in groundwater was quite high $(0.57 \mathrm{mg} / \mathrm{L}), 57$ times higher than the WHO standard drinking water $(10 \mu \mathrm{g} / \mathrm{l})$. The volume of 30 $\mathrm{ml}, 40 \mathrm{ml}, 50 \mathrm{ml}, 60 \mathrm{ml}$ groundwater was passed $10 \mathrm{~g}$ of laterite $4 \mathrm{ml} / \mathrm{min}$ material. The output shown in Table 2 is as follows:

Table 2. Result of groundwater treatment using laterite.

\begin{tabular}{lllll}
\hline Volume (ml) & As out (ug/l) & As in (mg/l) & Absorption capacity (mg/g) & Percentage (\%) \\
\hline 30 & 0.49 & 0.57 & 0.00171 & 99.91 \\
40 & 1.85 & 0.568 & 0.00227 & 99.67 \\
50 & 5.26 & 0.565 & 0.00282 & 99.08 \\
60 & 6.8 & 0.563 & 0.00338 & 98.80 \\
\hline
\end{tabular}

The results show that the ability of laterite treatment between groundwater contaminated by As is actually very positive. Experiment with real groundwater contamination As for efficiency up to $99.91 \%$. And the adsorption percentage As is a linear function with the sample volume using the equation $y=-0.039 x+101.1$ with $R 2=0.971$. From this equation it can be calculated that using 10 grams of material can handle $73 \mathrm{ml}$ of As contaminated water up to the standard of $0.01 \mathrm{mg} / \mathrm{l}$. The results obtained from the lateral adsorption experiments of As in various sample volumes as above establish the kinetic equations for the capacity testing and adsorbing mechanism of laterite materials.

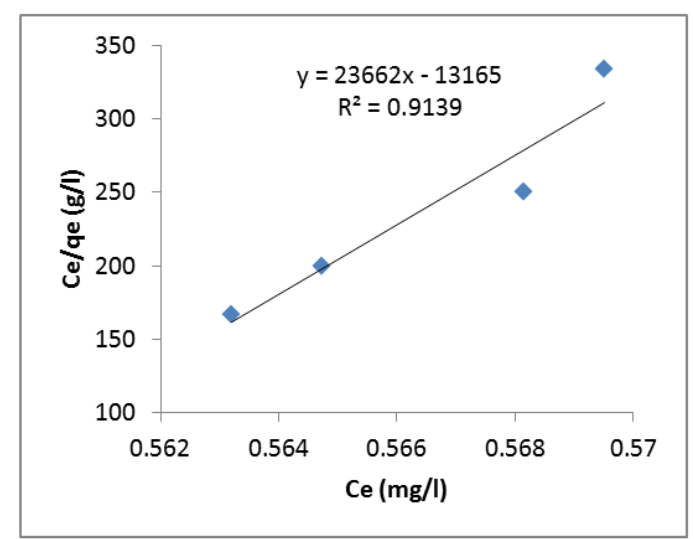

Figure 7. Langmuir isotherm model with groundwater treatment.
Based on the linear equation of isothermal graphs shown in Figures 7, the parameters were determined as R2 $=0.913, \mathrm{KL}$ constant $=1.797$ and adsorption capacity $\mathrm{qmax}=4.23 \times 10^{-5}$ $\mathrm{mg} / \mathrm{g}$. Thus, when using the same material to perform adsorption of As in real water samples, the results showed that the material has a high adsorption capacity As. Note that due to the fact that water also contains ingredients that interfere with the adsorption process such as phosphates and other inhibitors.

\section{Conclusion}

The chemical composition, surface morphology and surface area of the adsorbent material were also analysed using modern techniques such as EDX, SEM, BET. $\mathrm{Fe}^{3+}, \mathrm{Al}^{3+}, \mathrm{Si}^{6+}$ metal with $\mathrm{Al}_{2} \mathrm{O}_{3}: 21.84 \%, \mathrm{Fe}_{2} \mathrm{O}_{3}: 44.59 \%, \mathrm{SiO}_{2}: 21.81 \%$. The heterogeneous and porous surface morphology, the relatively large specific surface area $\left(30,712 \mathrm{~m}^{2} / \mathrm{g}\right)$, has demonstrated that laterite has many characteristics of a material with good adsorption capacity. This study show that laterite is a potential material for the treatment of As in water sources that can be applied in practice. Adsorption experiments in groundwater samples were also performed and the results showed that the treatment efficiency was $99.91 \%$. Langmuir's adsorption temperature gives the result of 1.797 and the absorption capacity q max is $4.23 \times 10^{-5} \mathrm{mg} / \mathrm{g}$. 


\section{References}

[1] T Trịnh, Y Tran, L. Đong, Environmental Engineering, Ha Noi Publisher, 2010.

[2] T. Nguyen, "Research on the production of adsorbents on the basis of basalt natural mineral materials, bee rock and clay to treat heavy metal and arsenic pollution Viet Nam", Academy Science and Technology vol. 11, pp. 13-15, 2010.

[3] T. Do, S. Hoang, H. Nguyen, "Laterite-rock and soil degradation of some midland provinces of northern Vietnam Ha Noi”, University of Technology vol. 17, pp. 22-27, 2012.

[4] N. Nguyen, Investigating the ability of arsenic in polluted water by tropical weathering soil, Ha Noi University of Water Resource, vol. 20, pp. 12-15, 2010.

[5] K. Nguyen, X. Nguyen, A. Le, Study on the treatment of arsenic in groundwater in some rural areas with iron (III) hydroxide, Ha Noi University of Science, vol. 33, pp. 1-3, 2012.

[6] Nguyen M, "Initial results to determine the non-charge point of Phuoc Long Basalt, Central Highlands by $\mathrm{pH}$ method", Viet Nam Academy Science and Technology, vol. 45, pp. 10-15, 2010.

[7] T. Vu, "Study on the treatment of arsenic in groundwater by modified zeolite manganese dioxide $\left(\mathrm{MnO}_{2}\right)$ ", Ha Noi University of Science, vol 32, pp. 30-33, 2012.

[8] D. Nguyen, "Synthesized nanometric manganese dioxide material on laterite carrier and investigated the adsorption capacity of the material for arsenic", Journal of Maritime vol. 34, pp. 17-23, 2011.

[9] S. K. Maji, A. Pal \& T. Pal, Arsenic removal from aqueous solutions by adsorption on lateritee soil, J Environ Sci Health A, vol. 42: 4, pp. 453-462, 2007.

[10] K. Sanjoy, Anjali P \& Tarasankar P Arsenic removal from real-life groundwater by adsorption on laterite soil, J. Hazard. Mat. vol. 151, pp. 811, 2008.

[11] Sanjoy K. Maji, Anjali Pal \& Tarasankar Pal, "Modeling and fixed bed column adsorption of As(V) on laterite soil". J Environ Sci Health A, vol. 42, pp. 1585-1593, 2007.

[12] A. Maiti, S. Das Gupta, J. K. Basu, S. De, "Adsorption of arsenite using natural laterite as adsorbent", Department of Chemical Engineering, Indian Institute of Technology, Kharagpur, Kharagpur 721302, India, 2007.

[13] S. K. Maji, A. Pal, T. Pal \& A. Adak, "Adsorption Thermodynamics of Arsenic on Laterite Soil", Department of Chemical Engineering, Indian Institute of Technology, Kharagpur, India, 2007.

[14] R. M. Canales, H. Guan, E. Bestland, J. H. Craig, T. Simmons, "Particle-size effects on dissolved arsenic adsorption to an Australian laterite", Environ. Earth Sci, vol. 68, pp. 2301-2312, 2012.

[15] N. Jahan, H. Guan, E. A. Bestland, "Arsenic remediation by Australian laterites", Environ Earth Sci, vol. 64, pp. 247-253, 2010 .

[16] S Mondal, A Roy, R Mukherjee, M Mondal, S Karmakar, S Chatterjee, M Mukherjee, S Bhattacharjee, S De, "A socio-economic study along with impact assessment for laterite based technology demonstration for arsenic mitigation" Sci Total Environ. vol. 583, pp. 142-152, 2017.

[17] V. Rathore, D. Dohare, P. Mondal, "Competitive adsorption between arsenic and fluoride from binary mixture on chemically treated laterite", J. Environ. Chem. Eng., vol. 4, pp. 2417-2430, 2016. 